\title{
Triethylenetetramine reduces some blood parameters in alloxan-induced diabetes mellitus in New Zealand white rabbit: evidence for histopathologic effects
}

\author{
Reza Golam Mohebbi ${ }^{1}$, Kaveh Azimzadeh ${ }^{2 *}$, Amir Amniattalab $^{3}$ \\ ${ }^{1}$ Graduate of Veterinary Medicine, Islamic Azad University, Urmia Branch, Urmia, Iran \\ ${ }^{2}$ Department of Clinical Sciences, Veterinary Faculty, Urmia Branch, Islamic Azad University, Urmia, Iran \\ ${ }^{3}$ Department of Pathobiology, Veterinary Faculty, Urmia Branch, Islamic Azad University, Urmia, Iran
}

Received: Dec 1, 2016, Revised: Dec 24, 2016, Accepted: Jan 22, 2017

\begin{abstract}
This study aimed to assess whether the triethylenetetramine (TETA) is impressed the plasma level of homocysteine (Hcy), total sialic acid (TSA) and cardiac troponin I (cTnI) as cardiovascular diseases risk factors, cystatin c (Cys c) and glucose along with histopathologic changes in alloxan induced diabetes mellitus in rabbit. Twenty number New Zealand white rabbits were assigned for this study. After induction of diabetes mellitus, TETA was orally administrated with different doses (10, 20, 40 $\mathrm{mg} / \mathrm{kg} / \mathrm{day}, \mathrm{A}, \mathrm{B}, \mathrm{C}$ groups respectively) for 6 months daily and group D (as positive control) not received TETA. In the following, above parameters, insulin and glucose were measured in the all groups. Furthermore, histopathologic evaluation was carried out for aorta, kidney and pancreas in the all ones. Amounts of plasma cTnI, Hcy, TSA, Cys c and glucose concentrations decreased significantly $(\mathrm{P}<0.01)$ in group $\mathrm{C}(40 \mathrm{mg} / \mathrm{kg} / \mathrm{day})$ compared with group $\mathrm{D}$ (positive control). In respect of insulin, normalizing of insulin occurred in group C (40 mg/kg/day) compared with group D (positive control). It is worth mentioning that during increasing of TETA dose, those levels decreased. In terms of histopathology, ameliorative and restoring effect of TETA on pancreatic beta-cells, glomeruli, renal tubules and aorta was determined in this study. The results suggested that TETA administration plays substantial role in tremendous alleviation of forenamed parameters and amelioration of beta-cells, renal glomeruli and tubules. Hence, TETA in the dose $40 \mathrm{mg} / \mathrm{kg} / \mathrm{day}$ may utilize in the part of human diabetes mellitus management including cardiovascular, renal diseases and glucose normalizing.
\end{abstract}

Keywords: Triethylenetetramine, diabetes mellitus, cardiovascular biomarkers, cystatin c, histopathology

Pharm Biomed Res 2016; 2(4): 44-51

\section{Introduction}

Diabetes mellitus (DM) belongs to one of the metabolic diseases which is completely characterized with insulin deficiency, resistance to the action of insulin, and/or both items (1). DM is known to involve the significant manifestations not only for premature atherosclerosis and renal disease but also for their rapid progression. Indeed, those complications are the substantial cause of death in DM, wherein chronic cardiovascular and renal complications and hyperglycemia are main adjectives (2). In addition, DM is associated with a series of metabolic alterations in which $\mathrm{Cu}^{2+}$ accumulation and tissue imbalance of $\mathrm{Cu}^{2+}$ are occurred in the extracellular matrix.
Copper $\left(\mathrm{Cu}^{2+}\right)$ as unbounded form, strongly possesses pro-oxidant feature in mammalian tissues and may trigger pathways that activates excessive generation of reactive oxygen species (ROS), such as the superoxide anion or hydroxyl radical (3) and their levels may elevate under pathological conditions and cause tissue damage (4). Macroangiopathy, microangiopathy, hypercholesterolemia, and hypertension in diabetic subjects are well associated with elevated serum $\mathrm{Cu}^{2+}$ concentration (5).

TETA (trientine) belongs to structure analog of linear polyamine compounds (spermidine and spermine) (5) 
and is characterized as a highly selective $\mathrm{Cu}^{2+}$ chelator along with an orphan drug trait wherein generally used for the treatment of Wilson's disease $(7,8)$. TETA usage boosts urinary $\mathrm{Cu}^{2+}$ excretion in patients with type 2 $\mathrm{DM}$ and streptozotocin-induced diabetes mellitus type I in rat (8). Furthermore, TETA ameliorates diabetesinduced cardiac dysfunction and left ventricular hypertrophy. Hence, TETA can be introduced as therapeutic agent in the treatment of diabetes mellitusinduced cardiovascular complications (9).

$\mathrm{Hcy}_{2 .}$ as a sulfur-containing amino acid, is involved in both endothelial cell damage in experimental animals and cardiovascular diseases in human and participates in oxidative stress occurrence. (10). Moreover, the atherogenicity of homocysteine might be associated with copper (11).

Sialic acid (SA), an acetylated derivative of neuraminic acid, is widely distributed in mammal tissues and body fluids and the localized SA at the end chain of many acute phase proteins can be used as a valuable indicator for diagnosis and prognosis of diseases such as cancer, cardiovascular disorders, nephropathies and pneumonia. On the other word, SA is known to be as a novel cardiovascular disease (CVD) biomarker (12) and increased total sialic acid (TSA) concentration is spotted as a risk factor for cardiovascular mortality in human (13). Moreover, higher serum TSA level has been documented in type 2 diabetic patients (14).

Cardiac troponin I (cTnI), as one of myofibrillar proteins, exists exclusively in myocardium and possesses valuable marker in awareness about the cardiomyocyte damage in the animals. Following the increase of cardiomyocyte permeability, cTnI releases into blood and is pointed out as a high-accurate biomarker for diagnosis of the heart muscle damage and positive correlation has been clarified between high serum cTnl and cardiomyocyte damage $(15,16)$. Generally, several studies have reported the changes of cTnI in diabetic rat $(16,17)$ but no study has been reported in rabbit with diabetes mellitus.

Cystatin-C (Cys-C) is a small $13-\mathrm{kDa}$ and nonglycosylated protein that appertains to the super family of cysteine proteinase inhibitors (18). It is independently filtered through glomerulus in the kidney, reabsorbed and catabolized in proximal renal tubules (19). Cys-C is known to be the most valuable endogenous serum biomarker in determination of renal function and specially, good candidate for glomerular filtration rate (GFR) in human medicine. Moreover, various conditions (inflammation, infection or malignancy) has not impression in the change of Cys $\mathrm{C}$ level (20). Moreover, an association between Cys $\mathrm{c}$ and cardiovascular diseases has been determined and in a study the role of Cys $\mathrm{c}$ has been reported as mortality prediction, diastolic dysfunction, incident heart failure $(21,22,23)$ and Niccoli et al. (24) reported Cys c increase during coronary artery atherosclerosis.

To the best of our knowledge, no study has been performed to investigate the TETA effect on cardiovascular biomarkers and cystatin $\mathrm{c}$ in diabetic rabbits. Hence, this is the first trial to evaluate abovementioned parameters during TETA administration in diabetic ones.

\section{Materials and method}

Protocol of study

In this study, twenty male New Zealand white rabbits ( $2.250 \mathrm{~kg} \pm 180$, age 4-5 months) were purchased from the animal house of veterinary faculty of Urmia university and were randomly divided into five groups (A, B, C, D, E) (each group four rabbits) in special cages under standard hygienic conditions and were allowed to use water and standard pellet ad libitum and 12:12 h light: dark at temperature $21-25^{\circ} \mathrm{C}$ with $39 \%$ humidity. Animal Research Ethics Committee of veterinary faculty of Islamic Azad University approved all experimental procedures (no: 0506215278).

\section{Induction of diabetes mellitus}

After 10 days of acclimatizing, dissolved alloxan tetra hydrate (Sigma, Aldrich) (in sterile distilled water) was intravenously injected $(80 \mathrm{mg} / \mathrm{kg})$ (25) through marginal vein and after two days, blood glucose above $250 \mathrm{mg} / \mathrm{dl}$ was observed in all of four groups (A, B, C, $\mathrm{D})$ as diabetic ones. It is worth mentioning that rabbits (group A, B, C, D) were fasted $12 \mathrm{~h}$ before and after alloxan injection. Also blood glucose was daily measured using glucometer GX (Ames, USA).

\section{TETA administration}

Thereupon, groups of $\mathrm{A}, \mathrm{B}$ and $\mathrm{C}$ received different doses of TETA (in distilled water) as gastric gavage daily: A) $10 \mathrm{mg} / \mathrm{kg} /$ day $\quad$ B) $20 \mathrm{mg} / \mathrm{kg} /$ day C) $40 \mathrm{mg} / \mathrm{kg} /$ day and group D not received any drug 
(positive control). Thus, there were two control group: group $\mathrm{D}$ as positive control and group $\mathrm{E}$ as negative control.

\section{Plasma preparation and analysis of biochemical} parameters

After 6 months of TETA administration, blood samples were taken via marginal vein and transferred to heparinized tubes and centrifuged at 6000 RPM for 10 minutes at $4{ }^{\circ} \mathrm{C}$. Plasma were separated and were kept in $-20{ }^{\circ} \mathrm{C}$ until analysis. TSA determination was carried out according to the method reported previously (26). Briefly, $400 \mu \mathrm{l}$ of serum were mixed with $3 \mathrm{ml}$ of $5 \%$ perchloric acid for $5 \mathrm{~min}$ at $100{ }^{\circ} \mathrm{C}$ and centrifuged at $1400 \mathrm{~g}$ for $4 \mathrm{~min}, 2 \mathrm{~mL}$ of supernatant were also mixed with $400 \mu \mathrm{L}$ of Echrlich reagent (pdimethylaminobenzaldehyde). Following incubation at $100^{\circ} \mathrm{C}$ for $15 \mathrm{~min}, 2 \mathrm{~mL}$ of distilled water was added on samples and the optical density of samples at $525 \mathrm{~nm}$ was read using a spectrophotometer (UV/Visible, Cecil, Italy). Hcy and glucose were detected according to the colorimetric method (Spectrophotometer, UV/Visible, Shekel 1500, Germany) (Parsazmoon co kits, Tehran, Iran). cTnI was detected by especial kit based on Elisa technique (Life diagnostics, Co, USA).
Insulin hormone level was measured by special kit for rabbit through Elisa technique (Kamiya Biomedical Co, USA). Finally, cystatin c (Cys c) was detected with (MyBio Source Co, USA) by Elisa method.

\section{Histopathological examination}

Tissue samples of healthy and diabetic animals from kidney, pancreas and aorta were taken and rapidly fixed in buffered formalin \%10. Thereafter, conventional paraffin wax embedding technique was performed in fixed specimens. Then, the sections were cut $5 \mu \mathrm{m}$ in thickness and were stained by Hematoxyline and Eosin (H\&E) method.

\section{Statistical analysis}

The data were denoted as Mean \pm SE. The statistical analysis of data was performed by one-way ANOVA and Tukey multiple comparison tests. The statistical package of SPSS 17 was allocated and significant level was set at $\mathrm{P}<0.01$ (Chicago, USA).

\section{Results}

Table 1 denotes alterations of Hcy, TSA, cTnI, Cys c, glucose and insulin in all groups. Significant decrease of plasma Hcy, TSA and cTnI concentrations were

Table 1 Effect of TETA in different dose on TSA, Hcy, CtnI, Cys c, glucose and insulin in control and diabetic groups as Mean $\pm \mathrm{SE}$

\begin{tabular}{lccccc}
\hline Parameters & $\begin{array}{c}\text { Control } \\
\text { negative group } \\
\text { (E) }\end{array}$ & $\begin{array}{c}\text { Control } \\
\text { positive group } \\
\text { (D) }\end{array}$ & $\begin{array}{c}\text { Diabetic } \\
\text { group received } \\
\mathbf{1 0 ~ m g / k g ~ T E T A ~} \\
\text { (A) }\end{array}$ & $\begin{array}{c}\text { Diabetic } \\
\text { group received } \\
\text { 20 mg/kg TETA } \\
\text { (B) }\end{array}$ & $\begin{array}{c}\text { Diabetic } \\
\text { group received } \\
\text { 40 mg/kg TETA } \\
\text { (C) }\end{array}$ \\
\hline TSA, mg/dl & $10.43 \pm 0.47^{\mathrm{a}}$ & $68.38 \pm 1.31^{\mathrm{b}}$ & $59.51 \pm 1.03^{\mathrm{c}}$ & $54.13 \pm 0.83^{\mathrm{c}}$ & $12.36 \pm 0.4^{\mathrm{d}}$ \\
$\mathrm{Hcy}, \mathrm{mg} / \mathrm{dl}$ & $4.03 \pm 0.18^{\mathrm{a}}$ & $18.66 \pm 0.14^{\mathrm{b}}$ & $14.77 \pm 0.51^{\mathrm{c}}$ & $12.19 \pm 0.57^{\mathrm{c}}$ & $4.84 \pm 0.37^{\mathrm{d}}$ \\
cTnI, pg/ml & $22.53 \pm 0.52^{\mathrm{a}}$ & $118.43 \pm 1.91^{\mathrm{b}}$ & $109.81 \pm 2.54^{\mathrm{b}}$ & $88.46 \pm 1.31^{\mathrm{c}}$ & $31.22 \pm 0.521^{\mathrm{d}}$ \\
Cys c, ng/ml & $0.27 \pm 0.004^{\mathrm{a}}$ & $3.57 \pm 0.02^{\mathrm{b}}$ & $3.12 \pm 0.029^{\mathrm{b}}$ & $0.89 \pm 0.01^{\mathrm{c}}$ & $0.31 \pm 0.002^{\mathrm{d}}$ \\
Glucose, $\mathrm{mg} / \mathrm{dl}$ & $129.25 \pm 1.89^{\mathrm{a}}$ & $298.54 \pm 2.05^{\mathrm{b}}$ & $174.50 \pm 1.67^{\mathrm{c}}$ & $182.47 \pm 2.55^{\mathrm{c}}$ & $132.28 \pm 2.14^{\mathrm{d}}$ \\
Insulin, ng/ml & $50.16 \pm 1.02^{\mathrm{a}}$ & $6.41 \pm 0.183^{\mathrm{b}}$ & $17.42 \pm 0.834^{\mathrm{c}}$ & $26.59 \pm 0.96^{\mathrm{d}}$ & $48.80 \pm 1.17^{\mathrm{e}}$ \\
\hline
\end{tabular}

Note: Data are expressed as mean \pm standard deviation. Different letters as superscript ${ }^{(\mathrm{a}, \mathrm{b}, \mathrm{c}, \mathrm{d})}$ in the row denote significant difference among groups. $(\mathrm{P}<0.01)$. For example, all superscripts are different in the insulin parameter, so, there are significant difference among groups. 
observed in group C (40 mg/kg/day) compared with group D (positive control). In addition, no significant changes were observed in TSA, Hcy and cTnI in the groups of $A(10 \mathrm{mg} / \mathrm{kg} /$ day $)$ and $B(20 \mathrm{mg} / \mathrm{kg} /$ day $)$ in comparison of group D (positive control). Similar issue was observed in glucose in the groups of A (10 $\mathrm{mg} / \mathrm{kg} / \mathrm{day})$ and $\mathrm{B}(20 \mathrm{mg} / \mathrm{kg} /$ day $)$ in comparison of group $\mathrm{E}$ (negative control). In respect of Cys c, remarkable increase was observed in group $\mathrm{D}$ (positive control) and group A (10 mg/kg/day) rather than group $\mathrm{E}$ (negative control). In contrast, notable decrease of Cys c was occurred in the groups of B $(20 \mathrm{mg} / \mathrm{kg} /$ day $)$ and $\mathrm{C}(40 \mathrm{mg} / \mathrm{kg} / \mathrm{day})$ in comparison of group D (positive control). In terms of insulin alterations, with increasing of TETA dose, insulin level was gradually elevated and significant difference of insulin was denoted in the various doses of TETA than group D (positive control). Furthermore, $40 \mathrm{mg}$ dose of TETA had tremendous effect in decrease of TSA, Hcy, cTnI, Cys c, glucose and increase of insulin level in diabetic rats.

In respect of histopathologic findings, results of present study were included: calcification in the aorta, beta-cells damage in the pancreas and glomerular and tubular injuries in diabetic group (D group), ameliorative effects of TETA on beta-cells of pancreas and kidney in group C ( $40 \mathrm{mg} / \mathrm{kg} /$ day) and absence of calcification in Media (M) layer of aorta artery in TETA administered group C (40 mg/kg/day).

In respect of histopathologic findings, results of present study were included: calcification in the aorta, beta-cells damage in the pancreas and glomerular and tubular injuries in diabetic group (D group), ameliorative effects of TETA on beta-cells of pancreas and kidney in group C (40 mg/kg/day) and absence of calcification in Media (M) layer of aorta artery in TETA administered group C (40 mg/kg/day) (Fig. 1, 2, 3).

\section{Discussion}

Cardiovascular diseases (CVD) and DM are inextricably associated and CVD is known to be the most common cause of mortality in diabetes mellitus (27), as well as Hcy possesses independent cardiovascular risk factor in DM and involves in oxidative stress (28). In this study, remarkable decrease $(\mathrm{P}<0.01 ; 4.84 \pm 0.37)$ of Hcy was observed in group $\mathrm{C}$ compared with groups of $\mathrm{E}$ and D. Uthus et al. (29) pointed out that hepatic betaine-homocysteine methyl transferase (BHMT), which catalyzes homocysteine to methionine conversion, is downregulated by $\mathrm{Cu}^{2+}$ deficiency and Tamura et al. (30) reported that $\mathrm{Cu}^{2+}$ deficiency causes low activity of methionine synthase. Therefore, we can consider that TETA administration decrease plasma homocysteine levels through $\mathrm{Cu}^{2+}$ chelation and $\mathrm{Cu}^{2+}$ shortage related molecular mechanisms.

In DM owing to overproduction of free radicals, cell damage occurs and one of vital cells that can affect with free radicals is known cardiomyocytes. In this study, considerable decrease $(\mathrm{P}<0.01 ; 31.22 \pm 0.521)$ of cTnI in the TETA administered group C (40 $\mathrm{mg} / \mathrm{kg} /$ day) were determined in comparison of the group D (positive control). TETA alleviates DMmediated many secondary complications (31). Atabek et al. (32) demonstrated elevation of cTnI in diabetic ketoacidosis patients which is in accordance with our study. The occurred heart damage in this study can attribute to DM-mediated anemia.

In numerous studies, chelators have provided protection against development of diabetic complications in animal models of diabetes mellitus $(2,4)$. TETA is classified as one of experimental therapeutics that acts to chelate excess $\mathrm{Cu}^{2+}$ in diabetic tissues and reduce oxidative stress and cellular damage (33) and in the recent years the vast attention has been paid on the effects of chemical components on cardiovascular function. Zhang et al. (34) revealed discernible effect of TETA on heart protection in diabetic rats which is in accordance of present study. Liu et al. (35) demonstrated unaltered expression levels of cTnI in hearts of diabetic rats which is not with our study. In addition, TETA can reinforce antioxidant defenses in diabetic models (6), hence participates in the maintenance of cardiomyocytes. The ameliorative effect of TETA on cardiomyocyte and increase of contraction power of the heart muscle has been identified. The possible mechanism of TETA for these advantageous effects is partly hypothesized to copper chelation, which enforces an antioxidant-mediated defense mechanism (31).

Previous studies have indicated that serum TSA concentrations are elevated in diabetes mellitus (both type 1 and type 2) with and without vascular complications (12). It is worth mentioning that a 

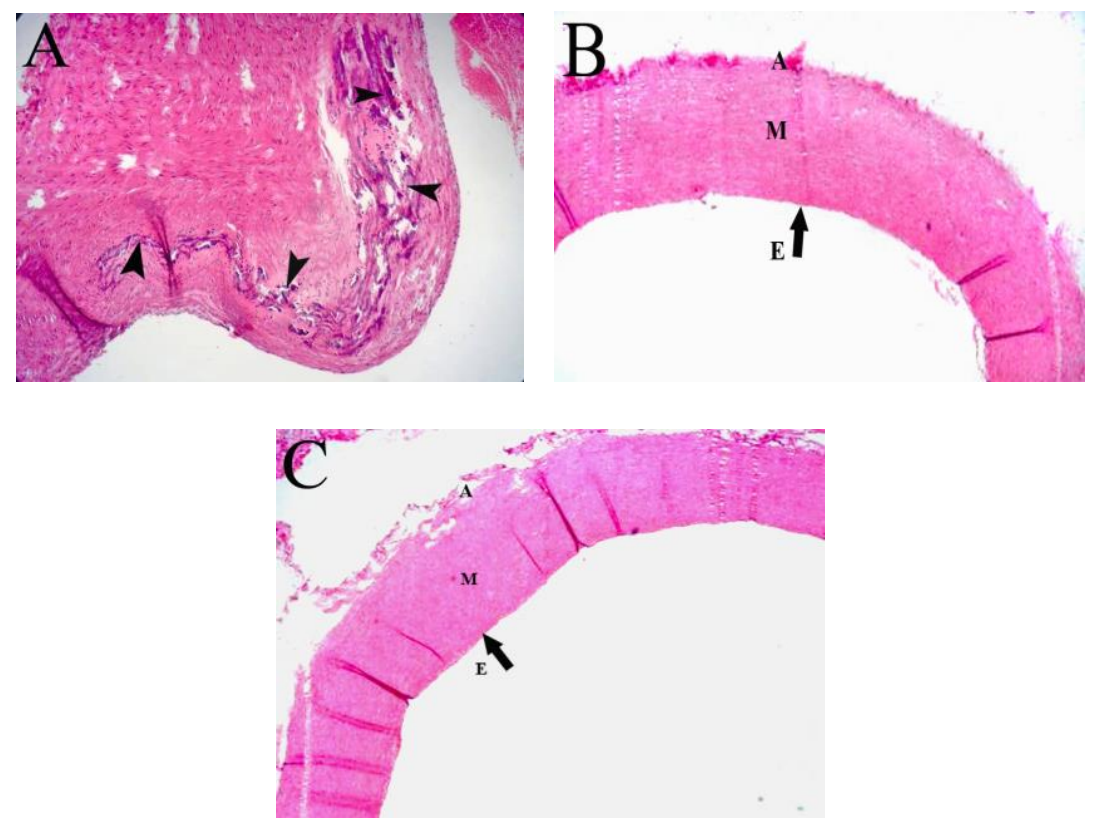

Figure 1 (A) Atherosclerotic evidence with calcified foci (arrowhead) in media layer of aorta artery in diabetic group. H\&E; X100. (B) Normal appearance of aorta artery in control group (group E). Endothelial (E), Media (M), Adventitia (A). H\&E; X400. (C) The absence of calcification in Media (M) layer of aorta artery in the TETA administered group C (40 mg/kg/day). H\&E; X400.
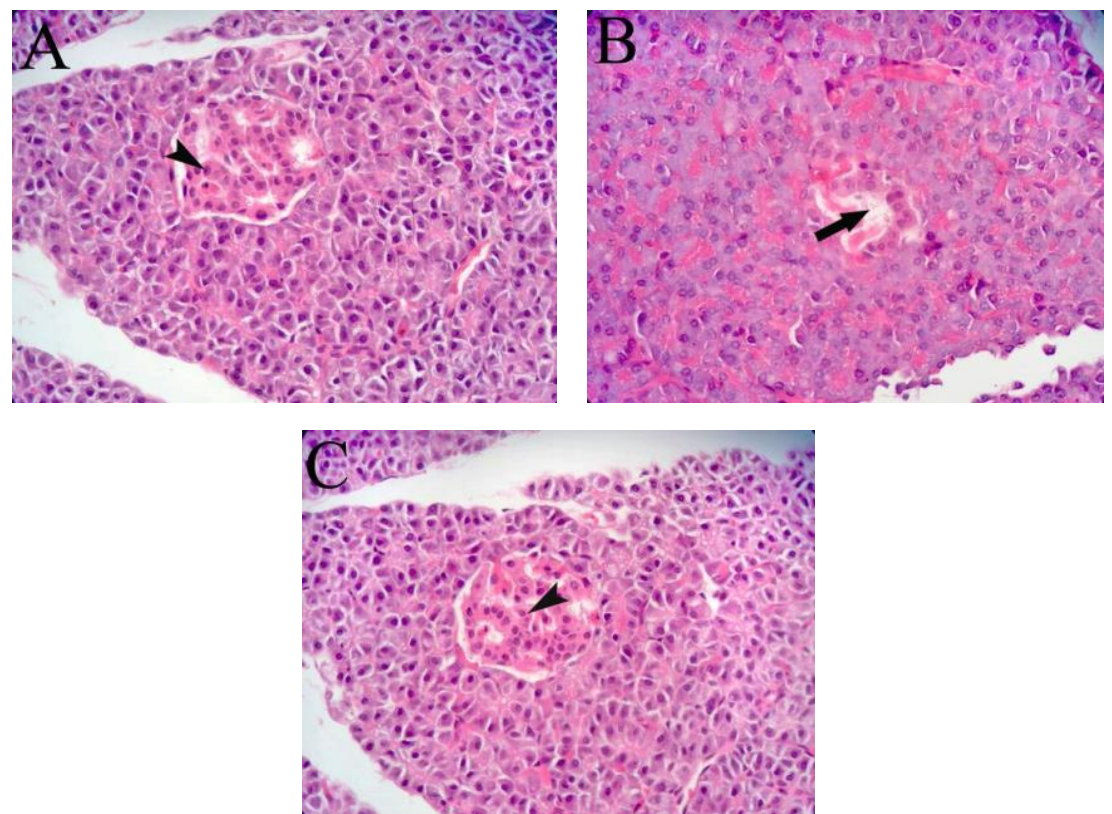

Figure 2 (A) Normal cellular (beta cells) density in Langerhans islets (arrowhead) in control group (E). H\&E; X400. (B) Cellular destruction and depletion in Langerhans islets with vacuolation (arrow) in diabetic group D. H\&E; X400. (C) Restore of pancreatic beta cells (arrowhead) similar control group in TETA administered group (C) (40 mg/kg/day). H\&E; X400. 

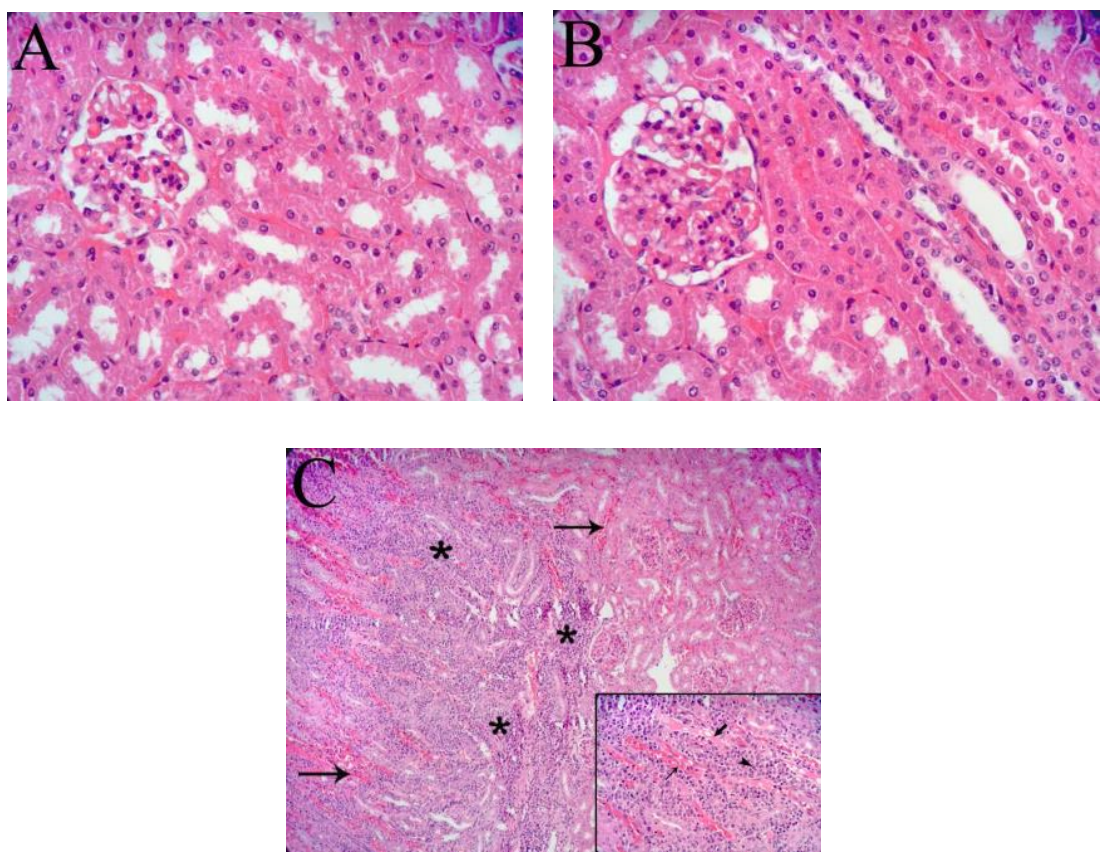

Figure 3 (A) Normal glomeruli and tubules in control ones (group E). H\&E; X400. (B) Normal glomeruli and tubules in TETA administered group (C) $(40 \mathrm{mg} / \mathrm{kg} / \mathrm{day})$. H\&E; X400. (C) (main figure): Interstitial nephritis with aggregation of lymphocytic inflammatory cells (asterisk) between tubules and hemorrhage (arrow) almost extended inter-tubular spaces in the diabetic group (group D). H\&E; X100. (inner figure): Higher magnification of interstitial nephritis, hemorrhage (thin arrow), lymphocytic inflammatory cells (arrowhead) and protein casts (thick arrow) between some tubules in the diabetic group (group D). H\&E; X400.

relationship between enhanced TSA with the occurrence of vascular complications is inevitable. Ekin et al. (1) demonstrated the higher level of TSA in diabetic patients. In present study significant decrease $(\mathrm{P}<0.01 ; 12.36 \pm 0.4)$ in the TSA level was revealed in group $\mathrm{C}$ compared with $\mathrm{D}$ and $\mathrm{E}$ groups. Rahman $e t$ al. (36) suggested the ameliorative effect of metformin in fall of sialic acid concentration than rosiglitazone in patients with diabetes mellitus type 2 . On the other word, Gracheva et al. (37) reported elevated activity of sialyl transferase in aortic intimal and plasma in atherosclerosis. Since, sialyl transferase involves in different metabolic pathways for adding sialic acid to glycoproteins and glycolipids (12). Thereby, it is likely that lower TSA may attribute to TETA effects on over expression and/or over-activity of sialyl transferase, consequently high demand of sialic acid and its transferring to glycoproteins and glycolipids during diabetes mellitus.

It is well known that DM-mediated nephropathy is one of main features of DM and high level of Cys $\mathrm{c}$ is attributed to secondary complications of DM can lead to end-stage renal disease (38). Low level of Cys c (P<
$0.01 ; 0.31 \pm 0.002)$ was occurred in the group C (40 $\mathrm{mg} / \mathrm{kg} /$ day). Daily TETA administration quells glomerular and kidney hypertrophy in the STZ-induced diabetes in rat (8). Moreover, Gong et al., in 2008 (4) reported TETA administration normalizes kidney tissue copper in DM and also suppresses whole-kidney and glomerular hypertrophy. Since $\mathrm{Cu}^{2+}$ overload in the tissue participates in induction of oxidative stress, as a result, it is most possible, TETA suppresses oxidative stress and subsequently leads to remodeling of kidney and ultimately Cys c level returns to normal range.

In terms of histopathologic findings, restoring and ameliorative effect of TETA on beta-cells and kidney was observed in the subgroup $\mathrm{C}$.

\section{Conclusion}

Since improving effects of TETA on heart muscle in diabetic subjects has been previously reported, the reducing effect of TETA on TSA, Hcy and cTnI concentrations, as cardiovascular risk factors, in diabetic rabbits along with histopathology findings, reveal substantial role of TETA in attenuation of diabetes mellitus-evoked cardiovascular complications. 
Meanwhile, reducing of Cys c, clarifies restoring and reconstruction effects of TETA in kidney which is confirmed through kidney histopathology. It is worth mentioning that, owing to high ameliorative role of TETA in dose of $40 \mathrm{mg} / \mathrm{kg} /$ day (subgroup C) on aorta, heart and kidney restoring, it is postulated that forenamed dose may assign as supplementary dose along with other drugs in the diabetic patients.

\section{Conflict of interest}

Authors had declared no conflict of interest

\section{References}

1. Ekin S, Mert N, Gunduz H, Meral I. Serum Sialic Acid Levels and Selected Mineral Status in Patients with Type 2 Diabetes Mellitus. Biol Trace Elem Res 2003;94:193-201.

2. Ugarte M, Brown M, Hollywood KA, Cooper GJ, Bishop PN, Dunn WD. Metabolomic analysis of rat serum in streptozotocin-induced diabetes and after treatment with oral triethylenetetramine (TETA). Genome Med 2012;4:35.

3. Da Silva F, Williams RJ. The biological chemistry of the elements: the inorganic chemistry of life. Second ed. Oxford University Press (UK): Clarendon; 2001. p. 418-35.

4. Gong D, Lu J, Chen X, Reddy S, Crossman DJ, Glyn-Jones S, et al. A copper(II)-selective chelator ameliorates diabetesevoked renal fibrosis and albuminuria, and suppresses pathogenic TGF-beta activation in the kidneys of rats used as a model of diabetes. Diabetologia 2008;51:1741-51.

5. Walter JY, Uriu-Hare KL, Olin KL, Oster MH, Anawalt BD, Critchfield JW, et al. Copper, zinc, manganese and magnesium status and complications of diabetes mellitus. Diabetes Care 1991;14:1050-6.

6. Lu J, Gong D, Choong SY, Xu H, Chan YK, Chen X, et al. Copper(II)-selective chelation improves function and antioxidant defences in cardiovascular tissues of rats as a model of diabetes: comparisons between triethylenetetramine and three less copper-selective transition-metal-targeted treatments. Diabetologia 2010;53:1217-26.

7. Cho HY, Blum RA, Sunderland T, Cooper GJ, Jusko WJ Pharmacokinetic and pharmacodynamics modeling of a copper-selective chelator (TETA) in healthy adults. J Clin Pharmacol 2009;49: 916-28.

8. Cooper GJ, Young AA, Gamble GD, Occleshaw CJ, Dissanayake AM, Cowan BR, et al. A copper(II)- selective chelator ameliorates left-ventricular hypertrophy in type-2 diabetic patients. Diabetologia 2009;52:715-22.

9. Kojda G, Harrison D. Interactions between $\mathrm{NO}$ and reactive oxygen species: pathophysiological importance in atherosclerosis, hypertension, diabetes and heart failure. Cardiovasc Res 1999;43:562-71.

10. Audelin MC, Genest J Jr. Homocysteine and cardiovascular disease in diabetes mellitus. Atherosclerosis 2001;159:497511.

11. Mansoor MA, Bergmark C, Haswell SJ, Savage IF, Evans $\mathrm{PH}$, Berge RK, et al. Correlation between Plasma Total
Homocysteine and Copper in Patients with Peripheral Vascular Disease. Clin Chem 2000;46:385-91.

12. Gopaul KP, Crook MA. Sialic acid: A novel marker of cardiovascular disease? Clin Biochem 2006;39:667-81.

13. Chen J, Gall MA, Yokoyama H, Jensen JS, Deckert M, Parving HH. Raised serum sialic acid concentration in NIDDM patients with and without diabetic nephropathy. Diabetes Care 1996;19:130-4.

14. Crook MA, Tutt P, Simpson H, Pickup JC. Serum sialic acid and acute phase proteins in type 1 and type 2 diabetes mellitus. Clin Chim Acta 1993;219:131-8.

15. Collinson PO, Gaze DC. Biomarkers of cardiovascular damage and dysfunction- an overview. Heart Lung Circ 2007;16:71-82.

16. Saravanan G, Ponmurugan $P$, Sathiyavathi M, Vadivukkarasi S, Sengottuvelu S. Cardioprotective activity of Amaranthusviridis Linn: effect on serum marker enzymes, cardiac troponin and antioxidant system in experimental myocardial infarcted rats. Int J Cardiol 2013;165:494-8.

17. Al-Rasheed NM, Al-Rasheed Nawal M, Hasan IH, Al-Amin MA, Al-Ajmi HN, Mahmoud MA. Sitagliptin attenuates cardiomyopathy by modulating the JAK/STAT signaling pathway in experimental diabetic rats. Drug Des Devel Ther 2016;10:2095-107.

18. Villa P, Jiménez M, Soriano MC, Manzanares J, Casasnovas P. Serum cystatin $\mathrm{C}$ concentration as a marker of acute renal dysfunction in critically ill patients. Critical Care 2005;9:13943.

19. Antognoni, MT, Siepi D, Porciello F, Rueca F, Fruganti G. Serum cystatin-C evaluation in dogs affected by different diseases associated or not with renal insufficiency. Vet Res Commun 2007;31:269-71.

20. Lassus J, Harjola VP. Cystatin C: a step forward in assessing kidney function and cardiovascular risk. Heart Failure Rev 2012;17:251-61.

21. Koenig W, Twardella D, Brenner H, Rothenbacher D. Plasma concentrations of cystatin $\mathrm{C}$ in patients with coronary heart disease and risk for secondary cardiovascular events: more than simply a marker of glomerular filtration rate. Clin Chem 2005;51:321-7.

22. Ix JH, Shlipak MG, Chertow GM, Ali S, Schiller NB, Whooley MA. Cystatin C, left ventricular hypertrophy, and diastolic dysfunction: data from the Heart and Soul Study. J Card Fail 2006;12:601-7.

23. Ix JH, Shlipak MG, Chertow GM, Whooley MA. Association of Cystatin C with mortality, cardiovascular events, and incident heart failure among persons with coronary heart disease. data from the Heart and Soul Study. Circulation 2007;115:173-9.

24. Niccoli G, Conte M, Della Bona R, Altamura L, Siviglia M, Dato I, et al. Cystatin $\mathrm{C}$ is associated with an increased coronary atherosclerotic burden and a stable plaque phenotype in patients with ischemic heart disease and normal glomerular filtration rate. Atherosclerosis 2008;198:373-80.

25. Puri D, Prabhu KM, Murthy PS. Mechanism of actions of a hypoglycaemic principle isolated in Fenugreek seeds. Indian J Physiol Pharmacol 2002;46.457-62. 
26. Sydow G. A simpllifield quick method for determination of sialic acid in serum. Biomed Biochim Acta 1985;44:1721-3.

27. Ryden L, Standl E, Bartnik M, Van den Berghe G, Betteridge $\mathrm{J}$, Boer MJ, et al. Guidelines on diabetes, pre-diabetes, and cardiovascular diseases. Eur Heart J 2007;28:88-136.

28. Azimzadeh K, Nasiri Y, Farzadnia H, Mamash Sargaz T, Najafi G. Plasma Malondialdehyde, Paraoxonase, Total Homocysteine and Adenosine Deaminase Levels in Citalopram Affected Rat. Terapevticheskii arkhiv 2014;86:58-62.

29. Uthus EO, Reeves PG, Saari JT. Copper deficiency decreases plasma homocysteine in rats. J Nutr 2007;137:1370-4.

30. Tamura T, Hong KH, Mizuno Y, Johnston KE, Keen CL. Folate and homocysteine metabolism in copper-deficient rats. Biochim Biophys Acta 1999;1427:351-6.

31. Cooper GJ. Therapeutic potential of copper chelation with triethylenetetramine in managing diabetes mellitus and Alzheimer's disease. Drugs 2011;71:1281-320.

32. Atabek ME, Pirgon O, Oran B, Erkul I, Kurtoglu S. Increased Cardiac Troponin I Concentration in Diabetic ketoacidosis. J Pediatr Endocrinol Metab 2004;17:1077-82.

33. Rezaei A, Heidarian, E. Co-administration of trientine and flaxseed oil on oxidative stress, serum lipids and heart structure in diabetic rats. Indian J Exp Biology 2013;51:64652
34. Zhang L, Ward ML, Phillips AR, Zhang S, Kennedy J, Barry $\mathrm{B}$, et al. Protection of the heart by treatment with a divalentcopper-selective chelator reveals a novel mechanism underlying cardiomyopathy in diabetic rats. Cardiovasc Diabetol 2013;12:123.

35. Liu X, Takeda N, Dhalla NS. Troponin I phosphorylation in heart homogenate from diabetic rat. Biochim Biophys Acta 1996;1316:78-84.

36. Rahman IU, Malik SA, Bashir M, Khan RU, Idrees M. Serum sialic acid changes in type 2 diabetic patients on metformin or rosiglitazone treatment. J Clin Pharm Therap 2010;35:685-90.

37. Gracheva EV, Samilova NN, Golovanova NK, Il'inskaya OP, Tararak EM, Malyshev PP, et al. Sialytransferase activity of human plasma and aortic intima is enhanced in atherosclerosis. Biochim Biophys Acta 2002;1586:123-8.

38. Susztak K, Raff AC, Schiffer M, Böttinger EP. Glucose induced reactive oxygen species cause apoptosis of podocytes and podocyte depletion at the onset of diabetic nephropathy. Diabetes 2006;55:225-33. 